\title{
Some observations on the seasonal distribution of dab, Limanda limanda, in the southern North Sea
}

\author{
R. Saborowski \& F. Buchholz \\ Biologische Anstalt Helgoland (Meeresstation); D-27483 Helgoland, Germany
}

\begin{abstract}
The seasonal changes in the population structure of dab were observed in intervals of four to six weeks from January 1993 to November 1994 at a fixed station northwest of Helgoland. The sex distribution was characterized by a reduced number of males during autumn and winter. In the autumn of both years, an immigration of large females was evident. During long periods in spring and summer, the population structure remained relatively constant. The observations indicate that dab in the Helyoland region carry out a seasonal migration between coastal waters and the sampling area. Seasonal changes of the population structure occurred at a relatively slow rate.
\end{abstract}

\section{INTRODUCTION}

Dab (Limanda limanda L.) is one of the most abundant fish species in the North Sea and therefore of considerable ecological relevance. This is particularly true in the south and southeast of the North Sea, in the coastal waters, and the Wadden Sea. Bohl (1957) carried out a basic investigation on the biology of dab and reported several aspects, including distribution, density, age, growth, and reproduction. Further work on the distribution of dab was contributed by Sahrhage $(1964,1967)$. An intensive study on the population structure of North Sea dab was performed by Lozán (1988), who found the highest densities in the area of the Doggerbank, the English coast, and the southern North Sea (German Bight).

Recently, the interest in dab has grown, since this species is considered to be suitable for ecotoxicological research and environmental monitoring programmes. In order to use dab in biological monitoring, however, a fundamental knowledge of the physiology, population dynamics and migration habits of the species is required. Migration in particular can lead to falsification and misinterpretation of physiological monitoring data. Therefore, in the present study we observed the population of dab at a fixed station northwest of Helgoland over a period of two years. Our special interest was focused on the question of whether or not the population structure remained constant over a longer period, and which kind of changes, that may indicate migratory activity, occurred during a seasonal cycle.

\section{MATERIAL AND METHODS}

Dab were caught northwest of Helgoland $\left(54^{\circ} 15^{\prime} N 7^{\circ} 45^{\prime} E_{i}\right.$ Fig. 1) at a depth of 25 to $30 \mathrm{~m}$. Samples were obtained from catches of the research vessels FK Uthörn and FS Heincke (in March 1993), carried out with a bottom trawl ( $70 \mathrm{~mm}$ mesh size). The net was 


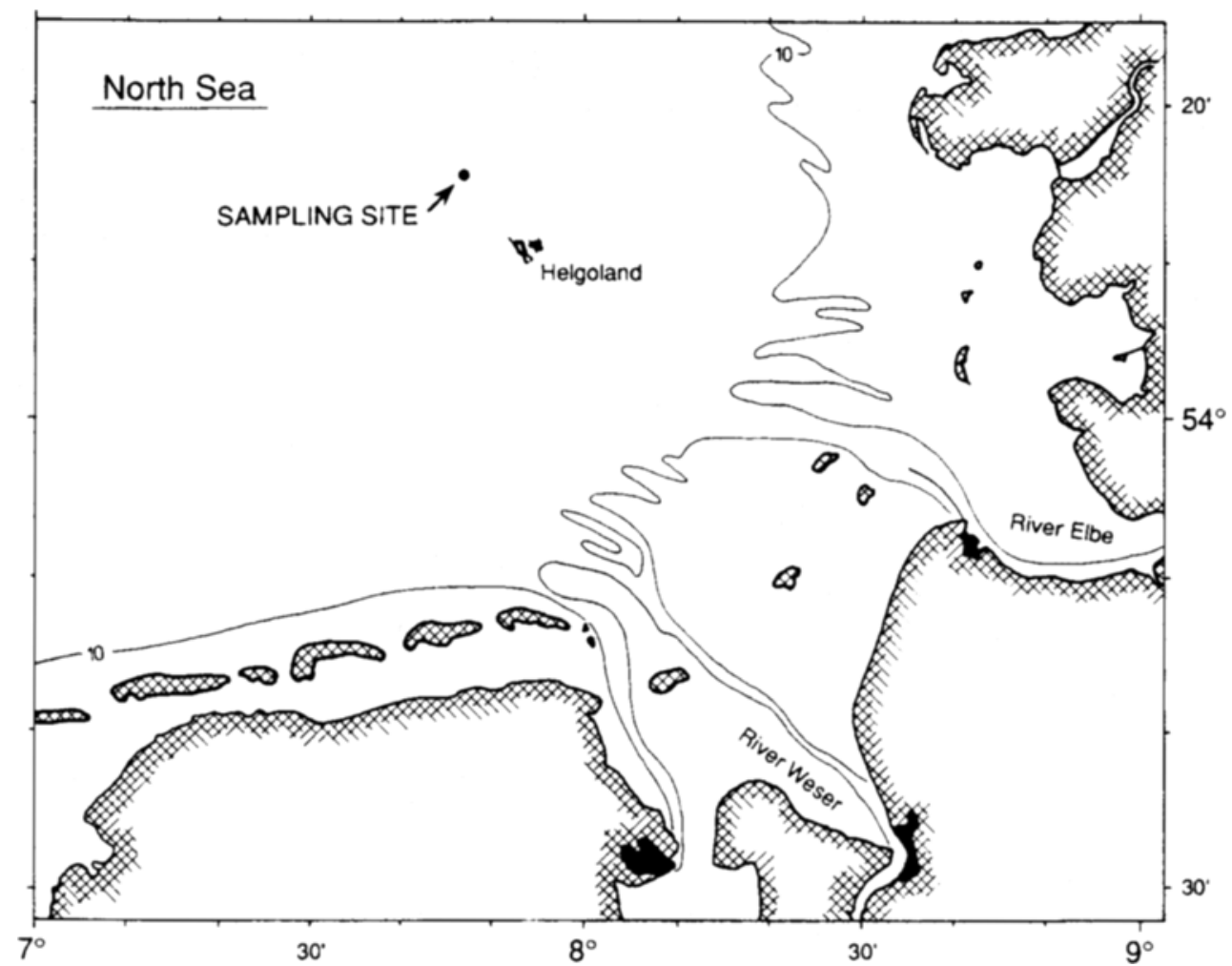

Fig. 1. Sampling site in the southern North Sea, northwest of the island of Helgoland

hauled for 10 to $15 \mathrm{~min}$ at a speed of 2.5 knots. Per haul either all dab were collected or, if the number of fish was high, a subsample of approximately 200 dab was selected randomly. The animals were transferred to the laboratory, where length, weight, and sex were determined. The condition factor (cf) was calculated in relation to the total weight according to the equation $\mathrm{cf}=$ total weight $\cdot 100 \cdot$ length ${ }^{-3}\left[\mathrm{~g} \cdot \mathrm{cm}^{-3}\right]$.

Sampling was carried out monthly from January 1993 to March 1994 and approximately every six weeks from March 1994 to November 1994. In December 1993 no sampling could be carried out due to severe storms.

The length data were compared with the Kruskal-Wallis one way analysis of variance on ranks. Significant differences between sampling periods were calculated by Dunn's pairwise multiple comparison procedure.

\section{RESULTS}

\section{Length and length frequency}

In general, females were larger than males throughout the period of investigation (Fig. 2). The median length of all females was $20.0 \mathrm{~cm}$. Between January and August ' 93 , the median length ranged between 18.5 and $20.0 \mathrm{~cm}$. From September through Novem- 


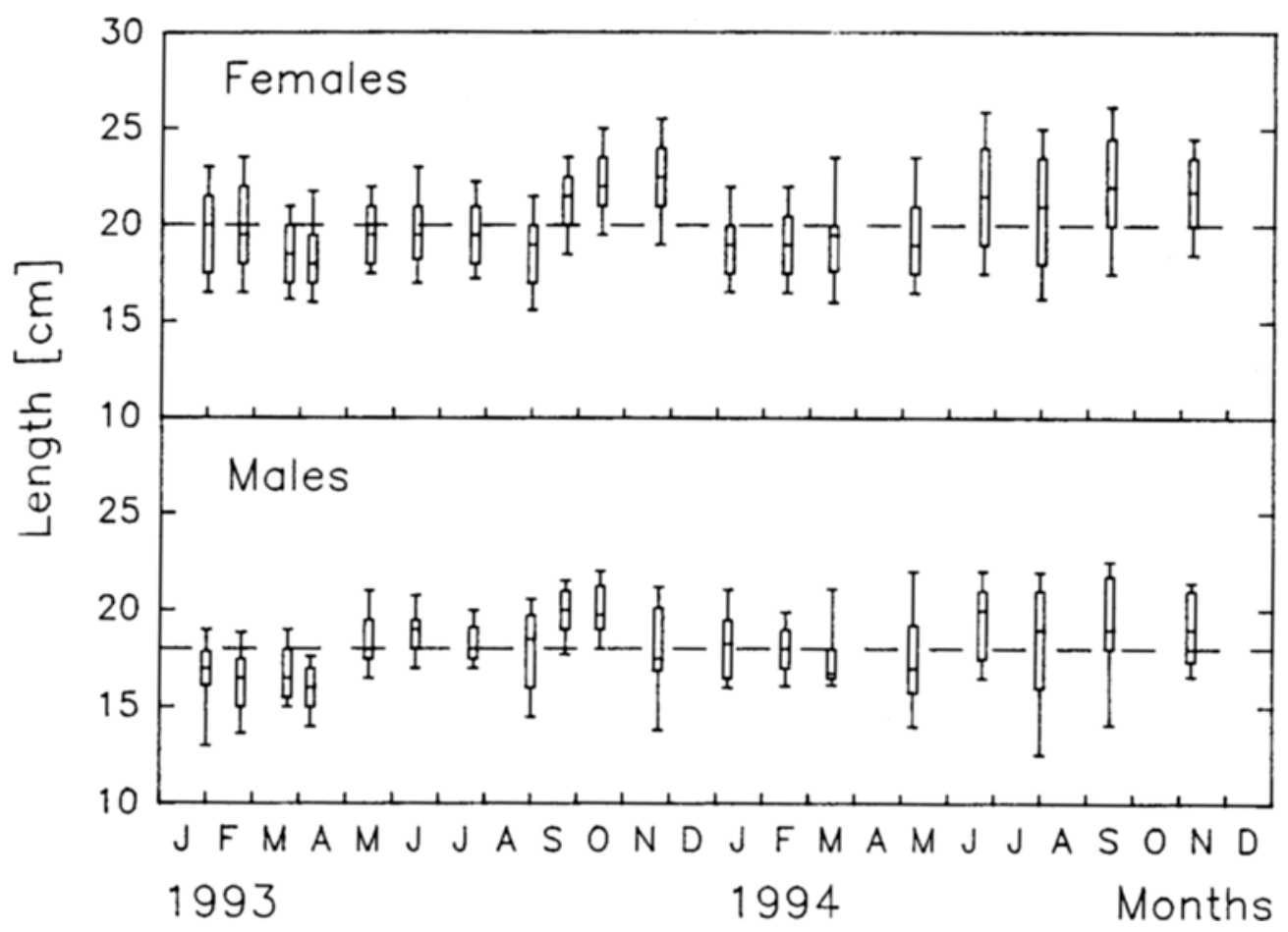

Fig. 2. Length of sampled dab. Boxes represent the median, the 25 th and 75 th percentiles. Bars indicate the 10th and 90th percentile points. Females: $\mathrm{n}=50-300$ (in March $1993 \mathrm{n}=19$ ). Males: $n=13-135$ (in January to March $1993 n=6-8$ ). Dashed lines represent the median length of all animals per sex (2637 females, 910 males)

ber '93, significantly larger females were observed with 21.5 to $22.5 \mathrm{~cm}$. In winter and spring ' 94 , the median length of females ranged again from 19 to $19.5 \mathrm{~cm}$. Larger specimens of 21 to $22 \mathrm{~cm}$ occurred in summer and autumn '94. The median length of all males was $18.0 \mathrm{~cm}$. From January '93 to April '93, males showed a uniform length of 16.0 to $17.0 \mathrm{~cm}$. Larger specimens occurred in May through to October with 18.0 to $20.0 \mathrm{~cm}$. From November '93 to May '94, the median length of males was again lower $(16.8$ to $18.3 \mathrm{~cm})$. An increase in length was observed during the summer of ' $94(19.0$ to $20.0 \mathrm{~cm})$.

The population at the sampling site was dominated by animals of 15 to $25 \mathrm{~cm}$ length (Fig. $3 \mathrm{a}-\mathrm{c}$ ). No animals smaller than $10 \mathrm{~cm}$ were caught, which may be due to mesh selection. In January '93, two prominent size classes of $17 \mathrm{~cm}$ and $21 \mathrm{~cm}$ appeared in females. This length corresponded to an age of 3 and 4 years, respectively (estimated from growth curves of Rijnsdorp et al., 1992). In the following months, until August '93, the length distribution was relatively constant (median of 19 to $20 \mathrm{~cm}$ ). In October and November larger females appeared and were estimated to be 5 years of age. In winter and spring ' 94 , the length distribution was again similar to that of summer of '93, with females of 18 to $19 \mathrm{~cm}$ in length predominating. In March '94, only few specimens were caught due to a heavy storm on the sampling day. Therefore, the length frequency is not representative for this particular month. In the summer of ' 94 , the relative number of large 
[\%] Kouanbary
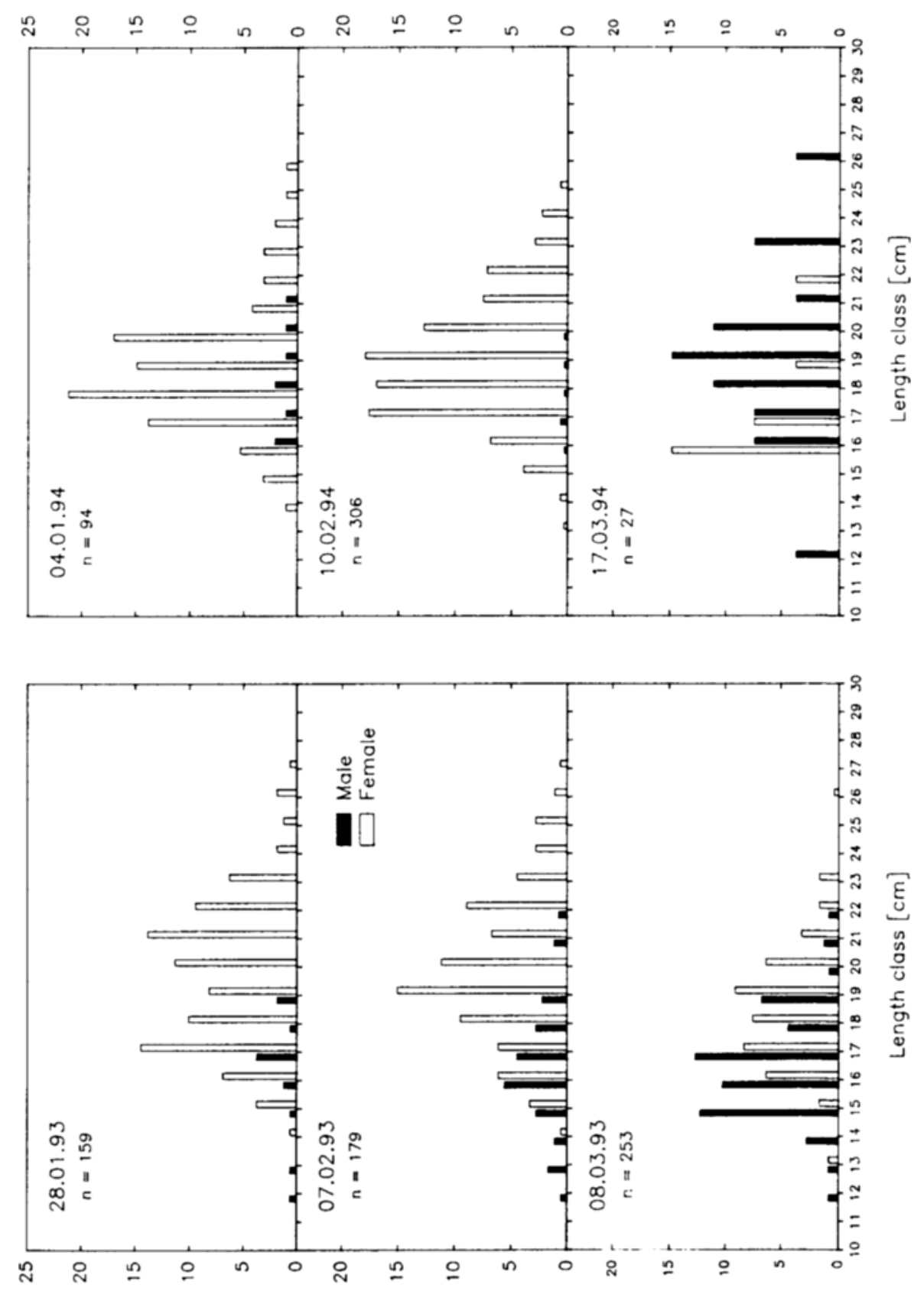

[x] Kouanbasy 
[\%] Kouanbad

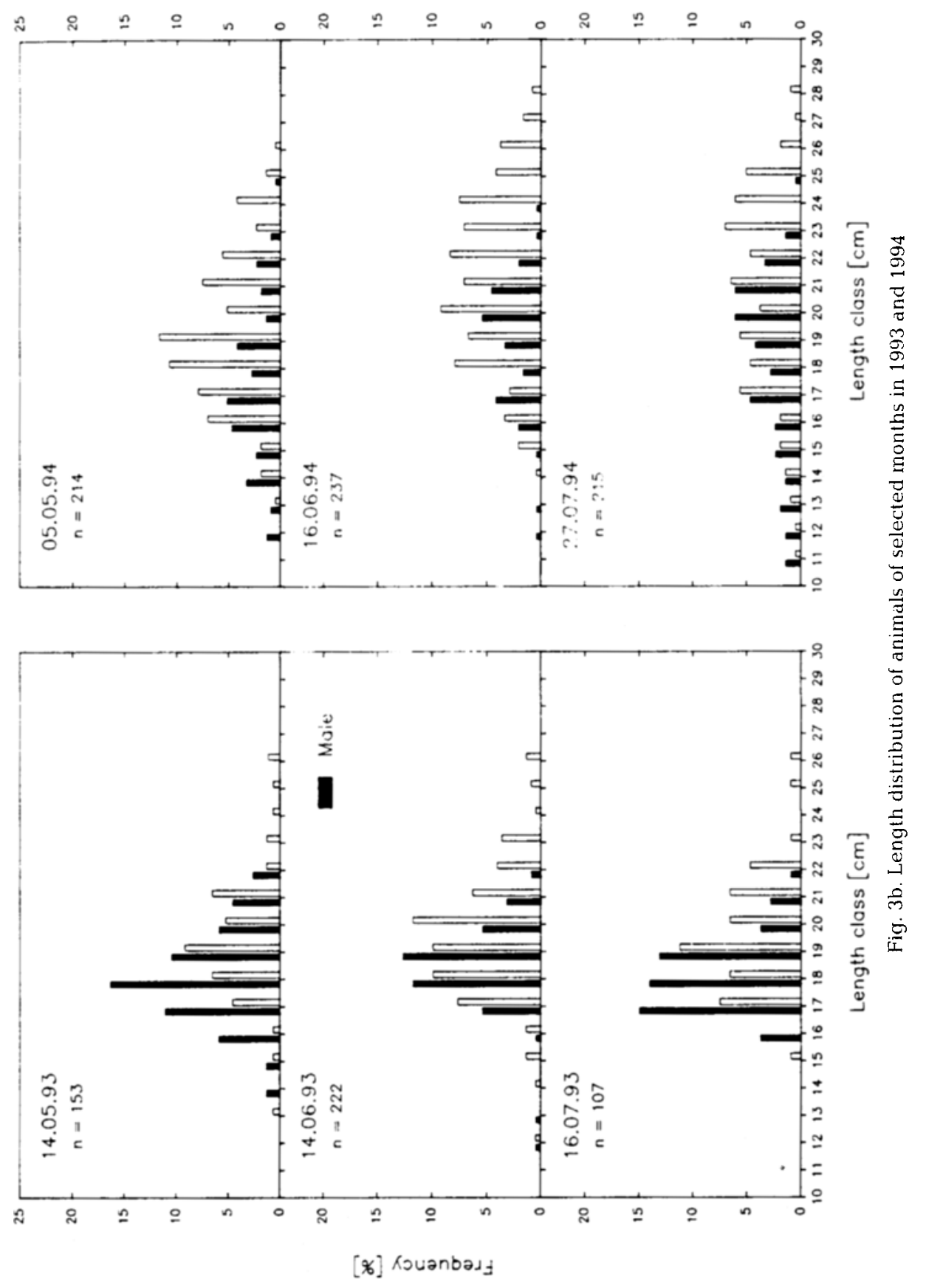


[\%] Kouanbasi
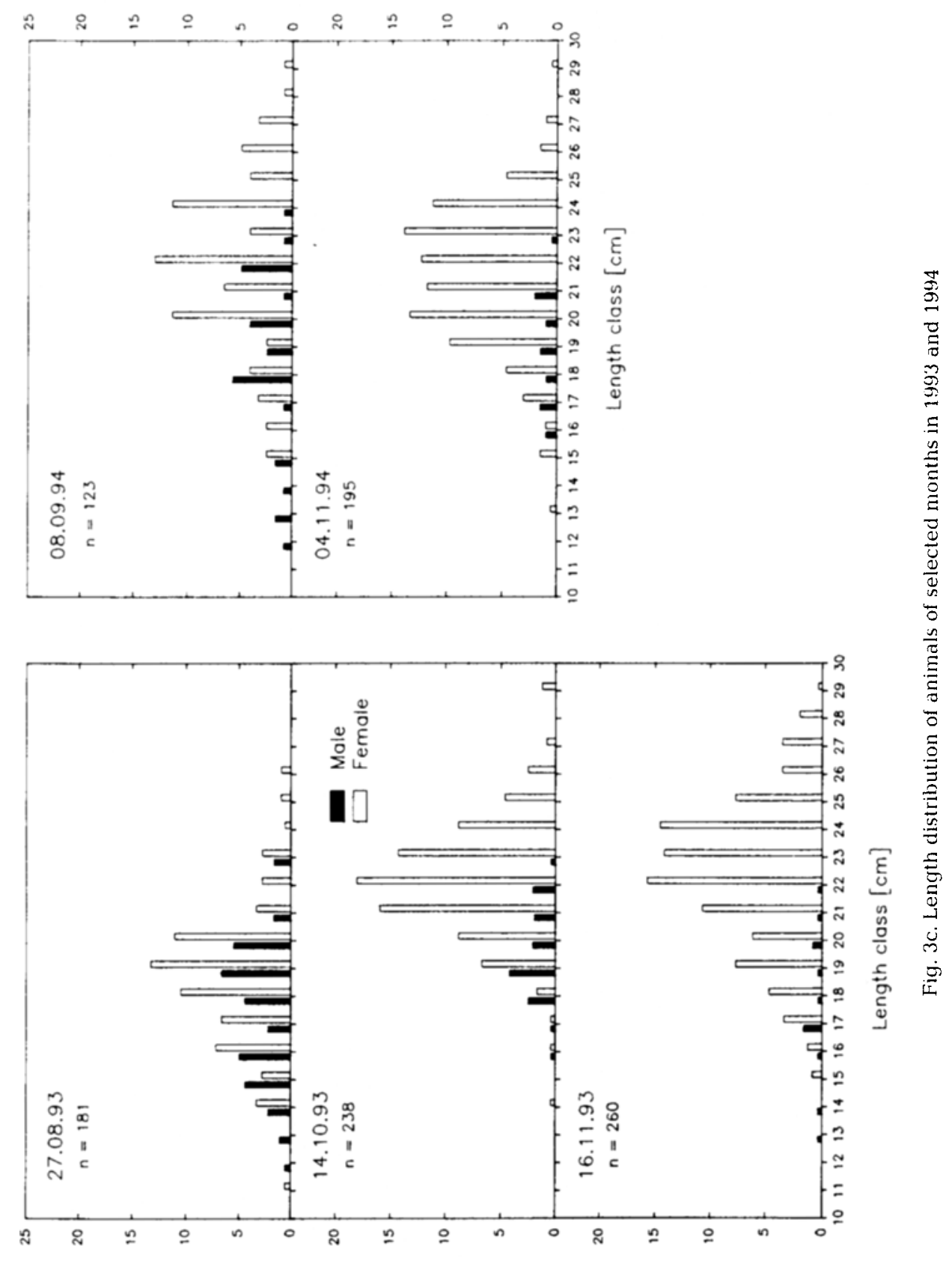

[\%] Kouanbady 
females of 20 to $25 \mathrm{~cm}$, as well as small females (11 to $15 \mathrm{~cm}$ ), increased, corresponding to an age span from 2 to 6 years. Furthermore, the biggest females of 26 to $29 \mathrm{~cm}$ were caught in this period. In autumn, the smaller females disappeared and the population was again dominated by animals of 20 to $25 \mathrm{~cm}$.

The distribution of males was relatively uniform from January to August ' 93 , although the number of smaller specimens was somewhat higher in March and August. The predominant length classes of 15 to $20 \mathrm{~cm}$ corresponded to an age of 3 to 5 years. In October '93, larger males of 18 to $22 \mathrm{~cm}$ appeared (5-6 years). In the summer of 1994, males covered a wider range of length classes than in 1993. In particular, small animals $(<15 \mathrm{~cm})$ were more abundant but also some animals of 22 to $24 \mathrm{~cm}$ were present. As in females, the percentage of larger animals was highest in autumn.

\section{Sex distribution}

In general, the population was dominated by females. In autumn and winter, the number of males decreased rapidly, reaching less than $1 \%$ of the total number of dab caught in January '94 (Fig. 4). From March to July the relation of both sexes ranged at about $50 \%$. In the summer of ' 94 , males were less frequent than females, reaching 30 to $40 \%$ of the total number of dab.

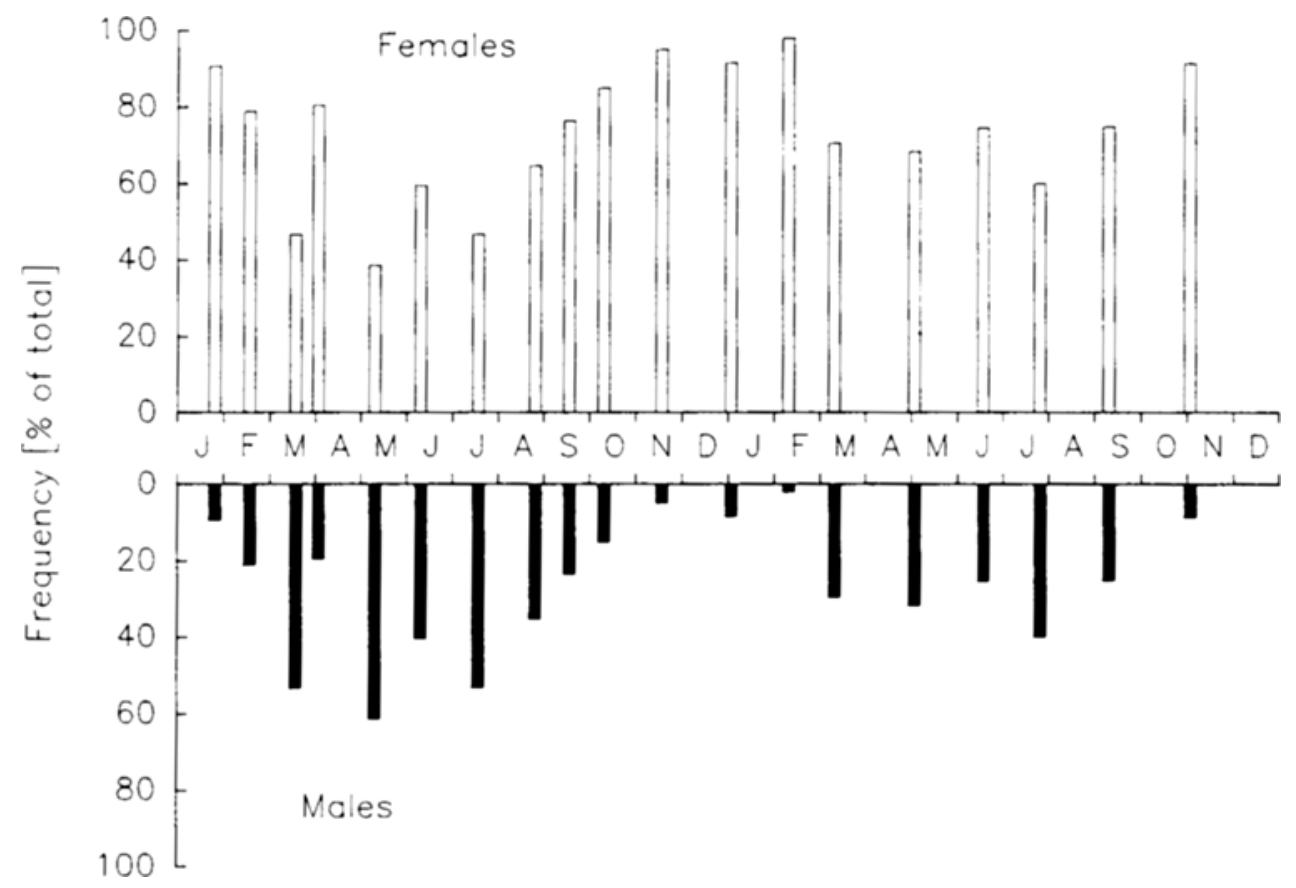

Fig. 4. Sex distribution of females and males expressed as percentage relation. The $x$-axis covers the months of 1993 and 1994 ( $\mathrm{n}=107-306$; in January $1994 \mathrm{n}=94$; in March $1994 \mathrm{n}=27$ ) 


\section{Condition factors}

The condition factors were nearly identical for both sexes during periods without reproductive activity, i.e. when no growth of gonads occurred (Fig. 5). The condition factor increased from May to September in each year. From October onwards, a sharp decrease of the condition factor was evident in males, reaching values of less than 0.9 in January and February. In females, the condition factor remained relatively constant until February, with a significant decrease in spring.

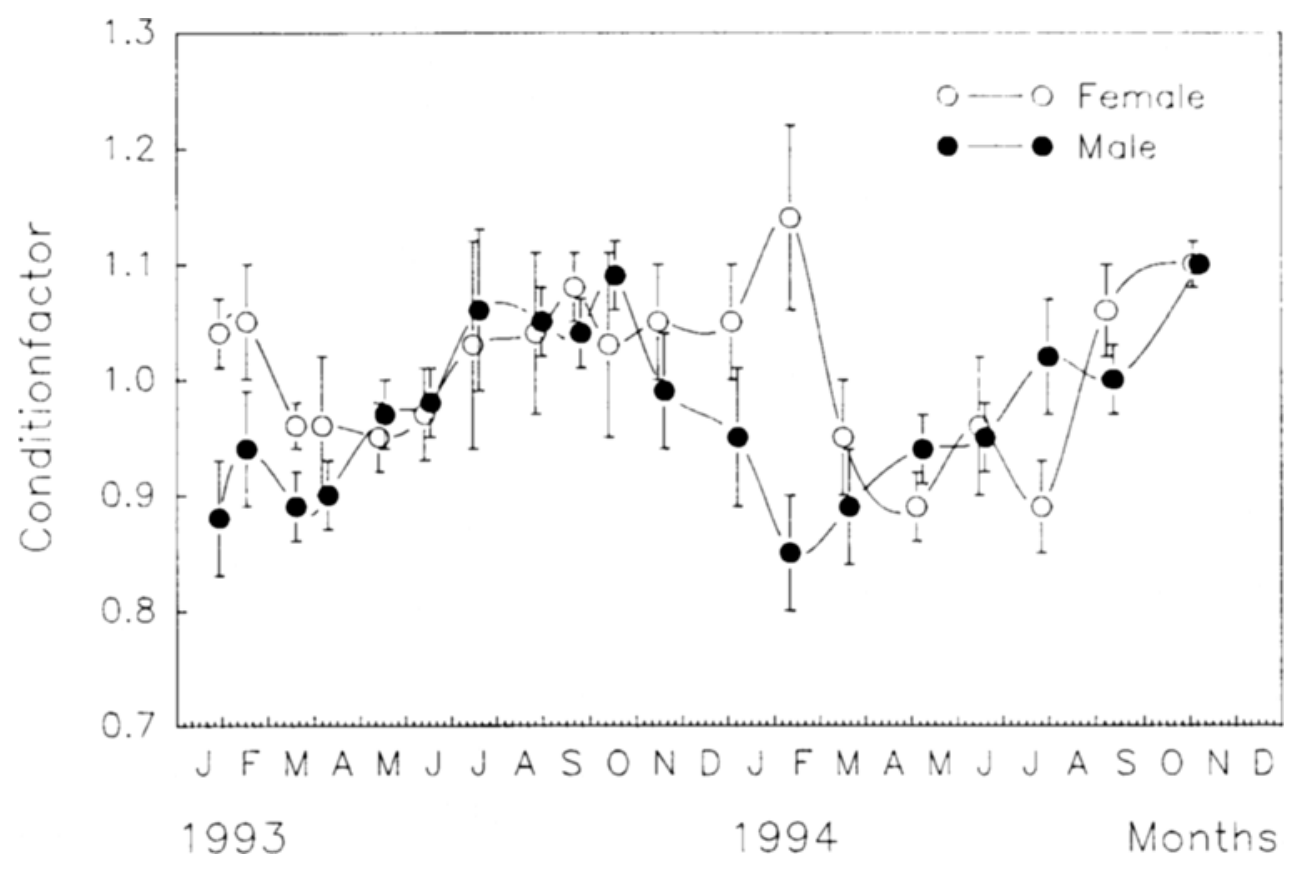

Fig. 5. Condition factors calculated in relation to the lotal weight. Error bars represent the $95 \%$ confidence interval of the mean. Females: $n=50-300$ (in March $1993 n=19$ ). Males: $n=13-135$ (in January to March $1993 n=6-8$ )

\section{DISCUSSION}

Most fish species perform migrations and thus potentially leave locations of toxicant exposure which may falsify monitoring data. The migrations of plaice in the North Sea were well investigated and it was shown that plaice can cover long distances within short periods (Reichard, 1915; Rauck, 1977). In the same way, flounder perform extensive migrations from coastal to offshore waters (Büther, 1987).

Our results show that the population of dab at the sampling site near Helgoland was dominated by females throughout the year. Nevertheless, a distinct seasonal variation in the sex distribution was evident. During the winter period, male dab disappeared almost completely from the area investigated, while females remained abundant. The sex ratio changed continuously through the seasons reflecting a cyclic annual succession. 
The length frequencies also showed that the population changed continuously and also over longer periods during the year. The population structure of both sexes remained relatively uniform during the spring and the summer of the first year of investigation. We observed the most significant change in the population structure in the autumn of ' 93 . Larger and, therefore, older females appeared at the sampling site while the males disappeared. Thereafter, the population structure again remained relatively constant. These animals disappeared in January, and the appearance of males was evident in spring.

The population structure of both sexes differed distinctly between the two years of observation, although showing similar trends. In the summer of ' 94 the spectrum of length classes, and thus age classes, was wider than in '93, indicating a higher heterogeneity of the population. This increase of heterogeneity did not appear rapidly but developed continuously in the course of several months.

With regard to the literature, these results can be integrated into a general model: Bohl (1957) investigated the spatial occurrence of dab along the German and Danish coast. During summer, females were predominantly present in the shallow coastal waters. Males were rare in this area, but became more abundant in deeper waters $(>15 \mathrm{~m})$ further away from the coast. He also postulated that in coastal areas dab carry out seasonal migrations towards the coast and back to offshore waters, and that the migration activity is age-, size-, and sex-dependent, respectively. Accordingly, predominantly older females migrate into shallow waters while males remain in deeper areas.

Our results support the idea that, with the onset of the offshore-directed-migration in autumn, the entire population moves towards the central North Sea. Accordingly, the local summer population, including the males, leaves the area around Helgoland while the coastal population, dominated by females, appears in this region. These animals leave the area again in late winter and the summer population returns. Similar observations in the autumn of the following year confirmed this model of seasonal migration, although in 1994 the older females appeared earlier than in 1993. The coastal population seems to stay around Helgoland during the winter and move back towards the coast in early spring.

These suggestions are in agreement with observations of Sahrhage $(1964,1967)$. He reported a high concentration of dab in the southern North Sea during summer, while in winter a more even distribution was observed. An exception, however, was evident around Helgoland with a high density of dab during summer and winter.

Apparently, the specific location of Helgoland has a distinct attraction for dab, which might be related to richer feeding grounds in the vicinity of the rocky intertidal zone, compared to other locations. The condition index, which is an indicator for the nutritive state, followed a seasonal cycle which is more distinct in males than in females (see also Saborowski \& Buchholz, 1996). Both sexes increased in weight during the summer season. In autumn, a sharp decrease of the condition index was obvious in males. Females, however, maintained a high condition index until spring, which was related to the growth of the gonads. The energy for gonad growth is obtained from food which must be available during this period. This would support the suggestion that the Helgoland region is an attractive feeding ground. Another reason for the high density of dab around Helgoland could be related to spawning habits. Dab are considered not to prefer distinct spawning grounds (Bohl, 1957). However, the high concentration of eggs off the Dutch, German and Danish coasts with a centre of concentration in the German Bight (Bohl, 
1957; Rijnsdorp et al., 1992) indicate that the region northwest of Helgoland might be a major spawning area, at least for animals living near the coast. Accordingly, this area could be an important destination in seasonal migration. Since dab also seem to avoid the low winter temperatures in the shallow coastal waters (Bohl, 1957), they may stay in the deeper layers of the waters surrounding Helgoland.

This interpretation of dab migration behaviour, however, cannot be easily adopted to other areas of the North Sea. In fact, dab are believed to remain for longer periods in specific areas and thus are more suitable for monitoring programs (Büther, 1990; Sleiderink et al., 1993). However, a migration study off the Belgian coast on dab showed that tagged mature dab could migrate over remarkably long distances (de Clerck, 1984). The main migration direction was northeast. Tagging experiments in the southern North Sea by Damm et al. (1991) revealed an increased migratory activity from January to April, which was probably associated with the time of spawning. Rijnsdorp et al. (1992) concluded from tagging experiments at different locations in the southern North Sea that a dab population at a specific sampling site is a transient aggregation originating from a large area. These different findings underline that particularly ecotoxicological and ecophysiological investigations should be paralleled by studies of the population structure. Although the individual routes of migration cannot be traced, the results provide important information about the homogeneity of the population and its variations from which migratory movements could be derived.

In conclusion, our results show that the population of females in the Helgoland area was more constant than that of males. Accordingly, it is of advantage in ecophysiological research to concentrate on investigations on female specimens, which are available all through the year for field sampling. Furthermore, the population structure was relatively constant over long periods indicating no rapid migrations, and thus observations on relatively sensitive, induced physiological parameters can be related to the sampling station.

Acknowledgements. We thank the crews of the research vessels "FS Heincke" and, especially, "FK Uthörn" for excellent support on board and Ms. M. Ziebarth and Mr. G. Sahling for technical dssistance. This work was supported by a scholarship of the Biologische Anstalt Helgoland.

\section{LITERATURE CITED}

Bohl, H., 1957. Die Biologie der Kliesche (Limanda limanda L.) in der Nordsee. - Ber. dt. wiss. Kommn Meeresforsch. 15, 1-57.

Büther, H., 1987. Erhöhte Hexachlorobenzol-Konzentrationen in Flundern (Platichthys flesus) der inneren Deutschen Bucht. - Infn Fischw. 34, 171-175.

Büther, H., 1990. Spatial and temporal trend in organochlorine contamination of dab (Limanda limanda) and flounder (Platichthys flesus) in the North Sea. - Arch. FischWiss. 40, 133-152.

Clerck, R. de, 1984. Tagging results of mature dab in the Southern Bight. - C.M.ICES, G11, 1-10.

Damm, U., Lang, T. \& Rijnsdorp, A. D., 1991. Movement of dab (Limanda limanda L.) in the German Bight and southern Bight: Results of German and Dutch tagging experiments in 1988, 1989. C.M./ICES, E22, 1-18.

Lozán, J. L., 1988. Verbreitung, Dichte und Struktur der Population der Klieschen (Limanda limanda L.) in der Nordsee mit Vergleichen $2 u$ den Populationen um Island und in der Ostsee anhand meristischer Merkmale. - Arch. FischWiss. 38, 165-189.

Rauck, G, 1977. Iwo German plaice tagging experiments (1970) in the North Sea. - Arch. FischWiss. $28,57-64$. 
Reichard, A. C., 1915. Ergebnisse der bisherigen internationalen Schollen-Markierungen in der Nordsee. - Wiss. Meeresunters. (Abt. Helgoland). 11, 37-64.

Rijnsdorp, A. D., Vethaak, A. D. \& Leeuwen, P. I. van, 1992. Population biology of dab Limanda Iimanda in the southeastern North Sea. - Mar. Ecol. Prog. Ser. 91, 19-35.

Saborowski, R. \& Buchholz, F., 1996. Annual changes in the nutritive state of North Sea dab. -J. Fish Biol. 49, 17.3-194.

Sahrhage, D., 1964. Über die Verbreitung der Fischarten in der Nordsee. Teil I, Juni-Juli 1959 und Juli 1960. - Ber. dt. wiss. Kommn Meeresforsch. 17, 165-278.

Sahrhage, D., 1967. Über die Verbreitung der Fischaxten in der Nordsee. Teil II, Januar 1962 und 1963. - Ber. dt. wiss. Kommn Meeresforsch. 19, 66-179.

Sleiderink, H.M., Boon, J.P. \& Everaarts, J.M., 1993. Levels of EROD activity, P450 1 A 1, and I. P450 in dab (Limanda limanda) from the southern North Sea in relation to PCB concentrations - preliminary results. -Mar. environ. Res. 35, 201-202. 